\title{
Tetrazoles: A new class of compound for crystallization modification
}

\author{
Massimiliano Massi, ${ }^{a}$ Mark I. Ogden ${ }^{a}$, Tomoko Radomirovic ${ }^{a}$ and Franca Jones, ${ }^{*}, a$ \\ Received (in $X X X, X X X)$ Xth $X X X X X X X X X 200 X$, Accepted Xth $X X X X X X X X X 200 X$ \\ First published on the web $X$ th $X X X X X X X X X 200 X$ \\ DOI: 10.1039/b000000x
}

Tetrazoles are a class of organic compound often used as carboxylic acid analogues. This anologous behaviour is shown to extend to crystallization modification, that is, tetrazoles are also able to influence crystal growth and morphology although in a 10 different manner to their carboxylate counterparts. All tetrazoles investigated thus far are shown to impact on barium sulfate and calcium carbonate crystallization to varying degrees. Thus, the tetrazoles represent a new class of crystal modifier.

The investigation of crystallization is an active field, with 15 much literature focussed on the impact that impurities or additives have on that process (for some reviews see 1-3). Crystallization control is desirable for many reasons, including controlling physical properties such as size and shape, complete inhibition (scale control), or growth 20 acceleration for more efficient processing. ${ }^{1,2}$ Thus, additives or impurities are a means of enforcing some control over the crystallization processes occuring. To this end, many additives or impurities have been investigated to date, ranging from small molecules, ${ }^{3}$ to polymeric species ${ }^{4}$ and even to 25 biological species. ${ }^{5}$ It is an area that we too, have been interested in, looking at factors such as the impact of stereochemistry, ${ }^{6}$ and functional groups, ${ }^{7}$ amongst others. Phosphonates are considered the most potent inhibitors, followed by sulfonates and carboxylates though this is 30 tempered by other factors such as stereochemistry etc. ${ }^{8}$ In this manuscript we present a new class of crystal growth modifier that to the authors' knowledge has never before used to modify crystallization, the tetrazoles.

${ }_{35}$ Over the past decades, methodologies to prepare tetrazole rings as well as the synthesis of tetrazole-containing compounds have been extensively investigated. ${ }^{9-11}$ The wide interest in this particular heterocycle stems from its many applications. The peculiar coordination chemistry of the 40 tetrazolate anion has been exploited for the preparation of coordination complexes ${ }^{12-14}$ and metal-organic frameworks ${ }^{15}$, 16 of transition metals and, more recently, lanthanoid elements. ${ }^{17-19}$ Tetrazoles have been exploited as analogues of carboxylic acids in medicinal chemistry formulations with 45 antifungal, antibacterial, anticancer, as well as antineurodegenerative activities. $^{20}$ In fact, the similar $\mathrm{pKa}$ of these two functional groups ${ }^{21}$ means the tetrazole ring can be utilised as a more metabolically stable (hence more biocompatible) surrogate of a carboxylic acid group. Figure 1 50 shows the structures of the tetrazole derivatives investigated in this work.

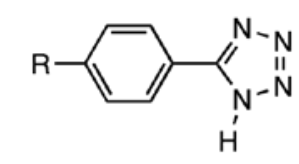

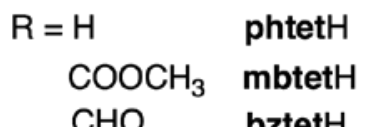

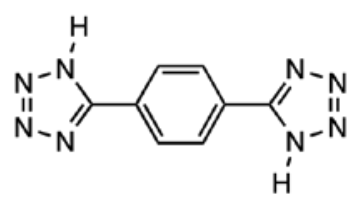

phtet ${ }_{2} \mathrm{H}_{2}$
55 Fig. 1 The tetrazole derivatives investigated in this work, 1H-tetrazol-5yl)benzene (phtetH), methyl 4-(1H-tetrazol-5-yl)benzoate (mbtetH), 4(1H-tetrazol-5-yl)benzaldehyde (bztetH), and 1,4-bis(1H-tetrazol-5yl)benzene ( phtet $_{2} \mathrm{H}_{2}$ )

60 All of these tetrazoles were prepared according to published procedures, ${ }^{10}$ by addition of $\mathrm{NaN}_{3}$ to the corresponding nitrile in presence of triethylammonium chloride. The tetrazoles were investigated at a concentration range of $0-1 \mathrm{~g} / \mathrm{L}$. The crystal growth experiments were carried out as described ${ }_{65}$ previously. ${ }^{7}$ In the case of barium sulfate, the crystallization process involved the standard addition of barium chloride to sodium sulfate, while for calcium carbonate the diffusion method (carbon dioxide diffusing into a calcium chloride solution) was employed (further details can be obtained in the 70 supplementary information).

Figure 2 shows the impact of the various tetrazole additives on the crystallization of barium sulfate at the $500 \mathrm{ppm}$ level.

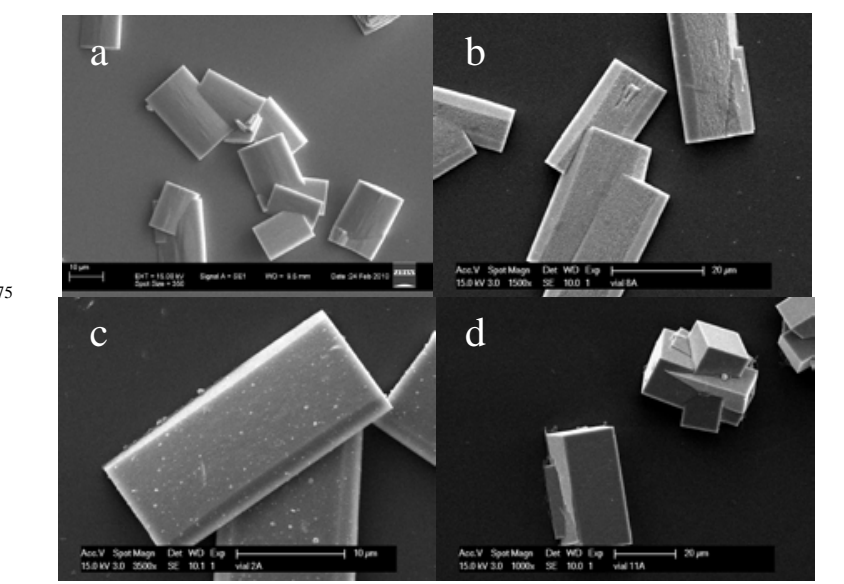

Fig. 2 SEM images of barium sulfate formed in the presence of (a) 0 mM tetrazole (b) $3.42 \mathrm{mM}$ phtet.'. (c) $2.45 \mathrm{mM}$ mbtet'. (d) $2.47 \mathrm{mM}$ phtet $_{2}{ }^{2-}$. 
It can be seen that the presence of phtet during barium sulfate crystallization results in particles with a larger aspect ratio (Figure 2b) but interestingly a rough, seemingly porous 5 (100) face is also observed (see supporting information, SIFig1). This was found to a much lesser extent when bztet ${ }^{-}$ was present (see supporting information, SIFig2), the particles almost being equivalent to the control particles. The presence of mbtet $^{-}$also resulted in barium sulfate with a larger aspect 10 ratio (Figure 2c). The addition of $\mathbf{p h t e t}_{\mathbf{2}}{ }^{2-}$ to growing barium sulfate showed the greatest impact with thick rhombohedral rods being formed (Figure 2d). These results show that tetrazole derivatives do have an impact on crystal growth, and that the chemical functionality of the additive does influence 15 the nature of that impact.

The larger aspect ratio observed for barium sulfate formed in the presence of all of the tetrazole molecules investigated here suggests a promotion of growth on the (001) relative to the 20 other faces, ${ }^{1}$ thus the tetrazoles appear to be promoting barium sulfate crystallization (at least on the (001) face relative to the other morphological faces present). The results obtained with phtet $_{2} \mathbf{H}_{2}$ can be contrasted with our previous work with the analogous carboxylate, terephthalic acid, ${ }^{3}$ which produced no 25 elongation of the barite crystals, but instead a mixture of crystals comparable to those found in the blank, along with clusters of smaller platelets, albeit at lower additive concentrations.

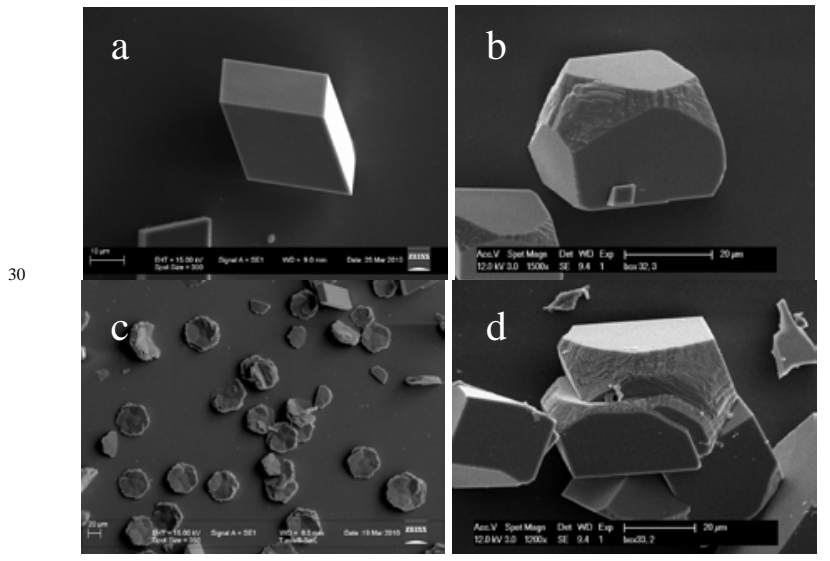

Fig. 3 Calcium carbonate crystallized in the presence of (a) $0 \mathrm{mM}$

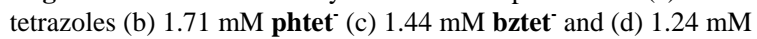
phtet $_{2}{ }^{2-}$

The presence of the various tetrazoles also has a significant impact on calcium carbonate crystallization (Figure 3 ). The presence of phtet $^{-}$, bztet ${ }^{-}$and phtet $_{2}{ }^{2-}$ (see supporting information for calcium carbonate crystallized in the presence 40 of mbtet, SIFig 3) results in an impact typical of many calcite inhibitors with rounding of the corners, compared to the typical rhombohedra observed in the blank (Figure 3a). ${ }^{22}$ The presence of bztet ${ }^{-}$, however, results in the stabilisation of hexagonal vaterite (confirmed with Raman spectroscopy, see 45 supporting information SIFig. 4). Normally, vaterite is observed as a transient species before the thermodynamic product (calcite) crystallises. Some additives, however, are known to stabilise vaterite. ${ }^{23}$ Finally, the tetrazoles appear to be more potent inhibitors of calcium carbonate crystallization 50 than the simple carboxylate-containing amino acids, which require $\sim 10 \mathrm{mM}$ for effects to be observed ${ }^{5}$ and also more potent than their carboxylic acid counterparts, though this needs to be verified due to concentration differences in the two studies. ${ }^{3}$ Tetrazole bztet $^{-}$appears to specifically inhibit 55 calcite formation and/or stabilize vaterite formation.

It can be conclusively stated that the tetrazole functionality has an effect on crystallization since in phtet and phtet $_{2}{ }^{2-}$ no other functional moieties are present. In addition, the increase 60 in the number of tetrazole groups from one to two shows an increased impact on morphology as would be expected based on the typical behaviour of more established carboxylate and phosphonate-based systems. ${ }^{1} \quad$ Finally, morphology experiments in the presence of sodium chloride at 65 concentrations in excess of those used in this study (even accounting for the 2 tetrazole groups in phtet $_{2}{ }^{2-}$ ) show that these effects are not due to the presence of sodium or chloride ions (see supplementary information SIFig 5). We hypothesise that the action of the tetrazole involves the nitrogen atoms as

70 well as an electrostatic interaction and we are pursuing this with further experimental and modelling investigations.

In conclusion, a new class of crystal modifiers, the tetrazoles, has been presented in this manuscript. This broadens the 75 'toolkit' of the scientist aiming to design additives to control crystallization, adding a new functional group to the more widely used anionic moieties such as carboxylates and phosphonates. Furthermore, while the tetrazoles are often used as analogues of carboxylates in various fields, tetrazole-based 80 crystal growth modifiers appear to have the potential to be significantly more potent than comparable carboxylates.

\section{Acknowledgements}

MM would like to thank the Australian Research Council for 85 funding (DP0985481).

\section{Notes and references}

${ }^{a}$ Curtin University of Technology, Department of Chemistry, GPO Box U1987, Perth WA Australia 6845. Fax: 6189266 4699; Tel: 6189266 7677; E-mail: F.Jones@curtin.edu.au

90

† Electronic Supplementary Information (ESI) available: [Experimental details, SEM images of barium sulfate formed in the presence of mbtet (close up) and bztet', calcium carbonate formed in the presence of mbtet; Raman specutrm of hexagonal calcium carbonate particles and calcium 95 carbonate formed in the presence of sodium chloride]. See DOI: $10.1039 / \mathrm{b} 000000 \mathrm{x} /$

1. F. Jones and M. I. Ogden, CrystEngComm, 2010, 12, 1016-1023.

2. H. Cölfen, Current Opinion in Colloid and Interface Science, 2003, 8, 100 23-31.

3. S. R. Freeman, F. Jones, M. I. Ogden, A. Oliviera and W. R. Richmond, Cryst. Growth Des., 2006, 6, 2579-2587. 
4. H. Cölfen and M. Antonietti, Langmuir, 1998, 14, 582-589.

5. C. A. Orme, A. Noy, A. Wierzbicki, M. T. McBride, M. Grantham, H. H. Teng, P. M. Dove and J. J. de Yoreo, Nature, 2001, 411, 775-779.

6. F. Jones, W. R. Richmond and A. L. Rohl, J. Phys. Chem. B., 2006, 110, 7414-7424.

7. F. Jones, M. Mocerino, M. I. Ogden, A. Oliviera and G. M. Parkinson, Cryst. Growth Des., 2005, 5, 2336-2343.

8. F. Jones, J. Clegg, A. Oliviera, A. L. Rohl, M. I. Ogden, G. M. Parkinson, A. M. Fogg and M. M. Reyhani, CrystEngComm, 2001,

$10 \quad$ 40, 1-3.

9. R. A. Henry and W. G. Finnegan, J. Am. Chem. Soc., 1954, 80, 39083911.

10. K. Koguro, T. Oga, S. Mitsui and R. Orita, Synthesis, 1998, 6, 910- 75 914.

15 11. Z. P. Demko and K. B. Sharpless, J. Org. Chem., 2001, 66, 79457950.

12. P. Lin, W. Clegg, R. W. Harrington and R. A. Henderson, Dalton Trans., 2005, 14, 2388-2394.

13. P. C. Andrews, P. C. Junk, M. Massi and M. Silberstein, Chem.

20 Commun., 2006, 3317-3319.

14. S. Stagni, S. Colella, A. Palazzi, G. Valenti, S. Zacchini, F. Paolucci, M. Marcaccio, R. Q. Albuquerque and L. De Cola, Inorg. Chem., 2008, 47, 10509-10521.

15. L. Carlucci, G. Ciani and D. M. Proserpio, Angew. Chem. Int. Ed., 1999, 38, 3488-3492.

16. A. Maspero, S. Galli, V. Colombo, G. Peli, N. Masciocchi, S. Stagni, E. Barea and J. A. R. Navarro, Inorg. Chim. Acta, 2009, 362, 43404346.

17. A. Facchetti, A. Abbotto, L. Beverina, S. Bradamante, P. Mariani, C.

30 L. Stern, T. J. Marks, A. Vacca and G. A. Pagani, Chem. Commun., 2004, 15, 1770-1771.

18. P. C. Andrews, T. Beck, B. H. Fraser, P. C. Junk and M. Massi, Polyhedron, 2007, 26, 5406-5413.

19. G. Marion, A. E. S, F. A. S, D. Renaud, P. Jacques, I. Daniel and M.

35 Marinella, Inorg. Chem., 2008, 47, 3952-3954.

20. R. J. Herr, Bioorg. Med. Chem., 2002, 10, 3379-3393.

21. R. N. Butler, Comprehensive Heterocyclic Chemistry, Pergammon, Oxford, U. K., 1996.

22. B. Njegic-Dzakula, L. Brecevic, G. Falini and D. Kralj, Cryst. Growth

40 Des., 2009, 9, 2425-2434.

23. N. Gehrke, H. Cölfen, N. Pinna, M. Antonietti and N. Nassif, Cryst. Growth Des., 2005, 5, 1317-1319. 